\title{
LASER ENERGY TREATMENT OF HAEMORRHAGES INTO THE ANTERIOR CHAMBER AND VITREOUS BODY* $\dagger$ EXPERIMENTAL AND CLINICAL RESULTS
}

BY

\author{
Z. FALKOWSKA, T. KẸCIK, D. MALINOWSKA, AND K. SZRETTER \\ Department of Ophthalmology, Medical Academy, Warsaw
}

THAT photocoagulation-particularly laser photocoagulation-influences the resorption of haemorrhages into the conjunctiva and retina is clear from observations reported by many authors (Olivella-Casals, 1963; Falkowska, Kẹcik, Puzewicz, Czerwińska, and Rutkowski, 1964; L'Esperance, 1965; Falkowska and Kẹcik, 1967).

Because similar results could be expected from the application of this method to haemorrhages. into the anterior chamber and vitreous, we have investigated the effect of laser energy on resorption of blood in such cases.

After a series of animal experiments had been successfully carried out (Kẹcik, Falkowska, Malinowska, and Szretter, 1967), laser coagulation with a Polish ruby laser, type KL 3, was used to treat haemorrhage into the anterior chamber and vitreous in human patients.

\section{Clinical Observations}

\section{A. Haemorrhages into the Anterior Chamber (15 cases)}

These cases were due to trauma (9), surgery (4), and choroiditis (2). The patients, whose ages ranged from 7 to 60 years, were subjected to fifteen to twenty exposures to laser radiation every day, using an output energy of 0.1 to 0.3 joule with additional focusing. After each series of exposures the blood level within the anterior chamber was visibly altered; the blood took on a frothy appearance and its colour changed from cherry-red to scarlet. On the following day in all patients the volume of blood in the anterior chamber had decreased, the blood had returned to its former cherry-red colour, and its level was re-established. The length of time required for complete resorption was from 2 to 6 days depending on the volume of blood in the chamber and the interval between the haemorrhage and the beginning of treatment.

\section{B. Haemorrhages into the Vitreous ( 28 cases)}

These cases were due to trauma (9), thrombosis (5), diabetes (5), arterial hypertension (4), Eales's disease (2), and high myopia (2). In one case the cause was not known. The patients' ages ranged from 16 to 60 years.

The method of treatment was the same as in Group A. Resorption occurred in from 1 to 3 weeks. In all the patients in this group the visual acuity did not exceed $0 \cdot 1$ and the fundus was not visible. The following members of this group deserve special attention:

* Received for publication May 12, 1967.

$\dagger$ Address for reprints: Department of Ophthalmology, Medical Academy, Oczki 6, Warsaw, Poland. 
Case 1. A man aged 52 years had a massive vitreous haemorrhage in the left eye; the visual acuity was reduced to counting fingers and the fundus was not visible. There was a past history of thrombosis of the upper branch of the central vein of the retina and a long history of arterial hypertension. After the first exposure to laser energy, the visual acuity improved to 0.25 , after the second it improved to 0.4 , and after the third to 0.8 with Sn 0.5 . The fundus could be clearly seen, and the patient was discharged in a satisfactory condition.

Case 2. A woman aged 67 years had a massive vitreous haemorrhage in the right eye. Visual acuity was reduced to hand movements. She had previously been treated for blood clotting with thrombocytopenia. After three exposures to laser radiation at intervals of 3 days, the blood was completely resorbed. The fundus was clearly visible and the visual acuity was $0 \cdot 8$. After 2 weeks, however, she returned with a fresh haemorrhage. The same treatment was applied and after four exposures the blood was again completely resorbed and the visual acuity improved to 0.8 . After another month the haemorrhage again recurred and laser energy treatment again gave a good result after six exposures, the visual acuity being 0.8 to 1.0 with Sn 0.5 , and the fundus clearly visible.

Case 3. A man aged 21 years had suffered blunt trauma to the left eye, and the visual acuity was reduced to perception of light. The anterior chamber and vitreous body were filled with blood. Laser photocoagulation was applied every day, with 29 exposures daily for 5 days using additional focusing, at from 0.1 to 0.2 joule. The blood in the anterior chamber was resorbed in 2 days, and that from the vitreous during the following 3 days. Examination with the biomicroscope revealed only isolated moving erythrocytes. The visual acuity improved to 6/18. The diminished visual acuity in this case was due to subluxation of the lens and rupture of the choroid near the macula.

\section{Discussion}

Our observations demonstrate that in all cases, independently of the aetiology, the time required for resorption depends on the amount of the extravasated blood and on the interval between the haemorrhage and the beginning of treatment. The earlier the treatment was begun the better was the result as judged by the visual acuity and the visibility of the fundus. In all cases the volume of extravasated blood diminished after each series of exposures. No side-effects of treatment were seen.

This method seems to be particularly valuable in the treatment of vitreous haemorrhages because it shortens the time required for blood resorption.

The chief factors in the action of ruby laser radiation on blood resorption are the coefficient of resorption and the mechanical effect.

(1) It follows from the analysis of the absorption spectrum of haemoglobin that the wave $6,343 \AA$ emitted by the ruby laser is only slightly absorbed by arterial blood. This coefficient is increased by about 5 per cent. with non-oxygenated haemoglobin (L'Espérance, 1965) and it increases markedly when blood clots are examined independently of their colour.

(2) Examination in vitro has shown that exposure of extravasated blood to laser radiation causes rupture of the erythrocyte membranes with passage of the haemoglobin into the plasma (Bessis, Gires, Mayer, and Nomarski, 1962; Pluta, 1966) and increased phagocytosis. It is known that coherent electromagnetic waves induce other oscillations-elastic vibrations with the frequency of ultrasound and hypersound (Blancard, Sorato, Blanlust, Iris and Liotet, 1964; Desvignes, Amar, Bruma, and Velghe, 1964). Their effective power is only slight but may help to loosen the structure of the clot, together with the phenomena of 
resonance due to the correspondence of the oscillation phase of laser radiation and the cyclic alterations of the intensity of this radiation during the "flash".

Most probably gas bubbles arise in the blood clot subjected to this energy as was observed in laser coagulation of the retina (Blancard and others, 1964; Falkowska and Kẹcik, 1967); this is probably the most important factor in dissolving the structure of the clot. This process permits the natural proteolytic enzymes to penetrate into the clot and increases the effective surface on which they may act.

Other factors influencing the process of resorption include irritation of the iris and consequent hyperaemia.

\section{Summary}

Clinical observations of ruby laser treatment of haemorrhage into the anterior chamber and vitreous are described. The satisfactory results indicate that this simple procedure is of great value in such cases.

\section{REFERENCES}

Bessis, M., Gires, F., Mayer, G., and Nomarski, G. (1962). C. R. Acad. Sci. (Paris), 255, 1010.

BlanCARD, P., Sorato, M., Blanlust, G., Iris, L., and Liotet, S. (1964). Bull. Soc. ophtal. Fr., p. 1009. Desvignes, P., Amar, L., Bruma, M., and Velghe, M. (1964). I Ibid., p. 759.

FALKowSKA, Z., and KeCIK, T. (1967). Klin. oczna, 37, 39.

-, PuZewicZ, Z., CZERwiŃSKA, W., and RUTKowski, S. (1966). Ibid., 36, 469.

KeCik, T., Falkowska, Z., Malinowska, D., and Szretter, K. (1967). Ibid., 37, 467.

L'Esperance, F. A. (1965). Arch. Ophthal. (Chicago), 74, 752.

Olivella-Casals, A. (1962). In "Problèmes actuels d'ophtalmologie", vol. 2, p. 31 (Bibl. ophthal., Fasc 60. I Int. Colloquium on Photocoagulation, Lausanne, 1959, ed. R. Dufour, G. Meyer-Schwickerath, and L. Fison).

Pluta, M. (1966). Biul. inform. Optyka, 1, 3. 